\title{
Behavioral Stress May Increase the Rewarding Valence of Cocaine-Associated Cues Through a Dynorphin/ $\kappa$-Opioid Receptor-Mediated Mechanism without Affecting Associative Learning or Memory Retrieval Mechanisms
}

\author{
Abigail G Schindler', Shuang Li' and Charles Chavkin*,' \\ 'Department of Pharmacology, University of Washington School of Medicine, Seattle, WA, USA
}

\begin{abstract}
Stress exposure increases the risk of addictive drug use in human and animal models of drug addiction by mechanisms that are not completely understood. Mice subjected to repeated forced swim stress (FSS) before cocaine develop significantly greater conditioned place preference (CPP) for the drug-paired chamber than unstressed mice. Analysis of the dose dependency showed that FSS increased both the maximal CPP response and sensitivity to cocaine. To determine whether FSS potentiated CPP by enhancing associative learning mechanisms, mice were conditioned with cocaine in the absence of stress, then challenged after association was complete with the $\kappa$-opioid receptor (KOR) agonist U50,488 or repeated FSS, before preference testing. Mice challenged with U50,488 60 min before CPP preference testing expressed significantly greater cocaine-CPP than saline-challenged mice. Potentiation by U50,488 was dose and time dependent and blocked by the KOR antagonist norbinaltorphimine (norBNI). Similarly, mice subjected to repeated FSS before the final preference test expressed significantly greater cocaine-CPP than unstressed controls, and FSS-induced potentiation was blocked by norBNI. Novel object recognition (NOR) performance was not affected by $U 50,488$ given 60 min before assay, but was impaired when given 15 min before NOR assay, suggesting that KOR activation did not potentiate CPP by facilitating memory retrieval or expression. The results from this study show that the potentiation of cocaine-CPP by KOR activation does not result from an enhancement of associative learning mechanisms and that stress may instead enhance the rewarding valence of cocaine-associated cues by a dynorphindependent mechanism.
\end{abstract}

Neuropsychopharmacology (2010) 35, 1932-1942; doi: I0.1038/npp.2010.67; published online 5 May 2010

Keywords: stress mechanisms; drug addiction; place preference; $\kappa$-opioid; novel object recognition; memory retrieval

\section{INTRODUCTION}

In human beings, stress exposure increases cocaine craving and induces relapse of cocaine use (Sinha et al, 2006), and in animal models, stressors facilitate cocaine self-administration, enhance conditioned place preference (CPP), and reinstate cocaine seeking (Goeders and Guerin, 1994; Haney et al, 1995; Shaham et al, 2000; McLaughlin et al, 2003; Covington and Miczek, 2005; Carey et al, 2007; Redila and Chavkin, 2008; Kreibich et al, 2009; Land et al, 2009). Although the adaptive responses to stress are generally protective, repeated and uncontrollable stress exposure can increase the risk of mood disorders (Gold and Chrousos, 2002). The mechanisms underlying these effects are still

*Correspondence: Dr C Chavkin, Department of Pharmacology, University of Washington, Box 357280, Seattle, WA 98195-7280, USA, Tel: + I 206543 4266, Fax: + I 206685 3822,

E-mail: cchavkin@u.washington.edu

Received 9 March 2010; revised 5 April 2010; accepted 7 April 2010 being resolved, but it is known that stress results in the release of important stress mediators including the dynorphin opioids (McLaughlin et al, 2003; Bruchas et al, 2007a; Land et al, 2008). Dynorphins are a family of endogenous neuropeptides derived from a common precursor and sharing structural features conferring selectivity for the $\kappa$-opioid receptor (KOR) (Chavkin and Goldstein, 1981; Chavkin et al, 1982; Chavkin, 2000). In addition, the dynorphins seem to encode the dysphoric and aversive responses to stress (Koob and Le Moal, 2005; Land et al, 2008, 2009; Zhou et al, 2008; Knoll and Carlezon, 2010). Together, these data suggest that KOR activation by endogenous dynorphins may mediate the negative affective changes caused by stress that increase drug addiction risk.

Earlier reports showed that prior activation of KOR potentiated the rewarding properties of cocaine subsequently administered in the CPP paradigm (McLaughlin et al, 2003; McLaughlin et al, 2006a,b). In these studies, KOR activation was caused either by exposure to repeated forced swim stress (FSS), repeated social defeat stress (SDS), 
or pharmacological activation of KOR by the selective agonist U50,488. We interpret these data to suggest that KOR activation by endogenous dynorphins induces a dysphoric state that enhances the rewarding properties of the subsequently experienced euphorigenic drug; however, the underlying mechanisms by which dynorphin may alter cocaine-CPP responses are not yet known.

To define those mechanisms consistent with Pavlovian learning theory (Tzschentke, 2007), the sequence of events during the CPP assay can be conceptualized as follows: (1) the animal is administered cocaine [an unconditioned stimulus (US)], (2) experiences a subjective rewarding euphorigenic effect [an unconditioned response (UR)], (3) learns to associate this UR with a specific environmental context [a conditioned stimulus (CS)], and when subsequently presented with the CS, (4) the animal exhibits approach behavior [a conditioned response (CR)] to the earlier cocaine-paired CS. The rewarding valence of the US is not static (Koob and Le Moal, 2008), and the rewarding properties of cocaine (Figure 1; coefficient a) and the valence of the cocaine-paired cues (Figure 1; coefficient c) may be controlled by external or internal parameters including the intrinsic hedonic state of the animal (Koob and Le Moal, 2005, 2008; Koob and Kreek, 2007). In the context of these experiments, rewarding valence is defined as the magnitude as well as the positive or negative sign of the hedonic response to cocaine.

On the basis of this conceptual scheme, the increase in the CR amplitude caused by earlier KOR activation could be a consequence of an increased rewarding valence of the cocaine ('a') or of the cocaine-associated cues (' $c$ '). Alternatively, because stress exposure is also known to affect associative learning mechanisms (Schwarzer, 2009) and memory retrieval (de Quervain et al, 1998), stressinduced dynorphin release may potentiate the CPP by enhancing the associative learning mechanisms ('b') or memory retrieval processes involved. To distinguish among these alternatives, we first measured the dose-response relationship of cocaine-CPP in non-stressed and stressed animals. We distinguished between the valence and the

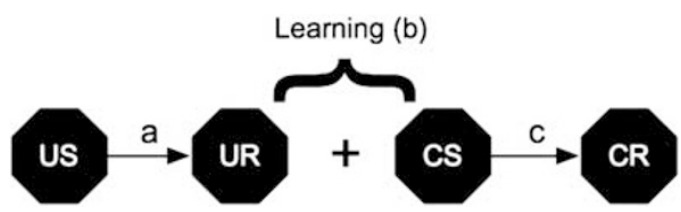

Figure I A cartoon diagramming the components underlying the CPP training paradigm. Conditioned place preference (CPP) is a technique used to evaluate preference for environmental stimuli that have been associated with a rewarding or aversive stimuli. In this conceptual analysis, the unconditioned stimulus (US) is cocaine, which produces an unconditioned response (UR) as a consequence of its euphorigenic (rewarding) effects. Stress experienced before cocaine may adjust the magnitude of the UR caused by cocaine (ie its valence) by the action of dynorphin on KOR (coefficient 'a'). Conditioned stimuli (CS) are the environmental cues in the CPP-conditioning chamber that become associated with the UR during the training phase. Factors controlling the strength of the associative learning events are denoted by coefficient 'b.' The conditioned response (CR) is the approach behavior to the drug-associated CS cues assessed during the final preference test, and we are testing the hypothesis that KOR activation may also affect the response to the CS by affecting the rewarding valence or memory retrieval processes controlling the amplitude of coefficient 'c.' associative learning hypotheses by adjusting the temporal relationship between KOR activation and cocaine administration. We tested whether KOR activation before the final preference test, but after the associative learning phases were already complete, also increased the CR. We hypothesize that if KOR activation enhances associative learning events, then the potentiation would be evident only when KOR activation and cocaine were temporally associated during the conditioning phase, but if KOR activation affects the rewarding valence of the stimulus or associated cues, then KOR activation should also potentiate CPP if presented just before the CS as diagrammed in Figure 3a. Finally, we used the novel object recognition (NOR) assay to investigate the effects of KOR activation on memory retrieval and expression mechanisms.

\section{MATERIALS AND METHODS}

\section{Animals and Housing}

Male C57Bl/6 mice (Charles River Laboratories, Wilmington, MA) weighing 20-30 $g$ were used. Mice were group housed, 2-4 per cage, in self-standing plastic cages $(28 \mathrm{~cm} \mathrm{~L} \times$ $16 \mathrm{~cm} \mathrm{~W} \times 13 \mathrm{~cm} \mathrm{H}$ ) lined with 'Bed-o'Cobs' in an isolated, decentralized housing room. Housing room was maintained on a 12-h light/dark cycle (lights on at 1900 hours) with food pellets and water available ad libitum. Animal procedures were approved by the University of Washington Institutional Animal Care and Use Committee.

\section{Drugs and Chemicals}

Cocaine-HCl, norbinaltorphimine (norBNI)-HCl, and $( \pm)$ U50,488 were provided by the National Institute of Drug Abuse Drug Supply Program (Bethesda, MD). Drugs were dissolved in $0.9 \%$ saline just before injection.

\section{Forced Swim Stress}

Wild-type (WT) C57Bl/6 mice were exposed to a modified Porsolt FSS as described earlier (Porsolt et al, 1977; Pliakas et al, 2001; McLaughlin et al, 2003). For studies involving KOR activation before drug training (Figure 2a), the experimental protocol was as described earlier (McLaughlin et al, 2003). Studies involving KOR activation before the final preference test examined the effects of a single episode of stress exposure (Figure $4 \mathrm{a}$ ) or repeated stress exposure (Figure 4b) in different sets of mice. To examine the effects of acute stress exposure, mice were exposed to one $15 \mathrm{~min}$ swim in $30 \pm 1{ }^{\circ} \mathrm{C}$ water on day 4,10 or $45 \mathrm{~min}$ before the final preference test. To examine the effects of repeated stress exposure, mice were exposed to one $15 \mathrm{~min}$ swim in $30 \pm 1^{\circ} \mathrm{C}$ water $2-4 \mathrm{~h}$ after completion of cocaine training on day 3 , and then four 6 min swims in $30 \pm 1^{\circ} \mathrm{C}$ water on day 4 , $10 \mathrm{~min}$ before the final preference test. After each trial, mice were removed, towel dried, and returned to their home cage for at least $6 \mathrm{~min}$ before further testing. Time spent immobile was recorded using video capture (Canon ZR90) from above and analyzed using Noldus Ethovision software (version 3.0; Noldus, Wageningen, The Netherlands). To confirm dynorphin release and subsequent KOR activation 

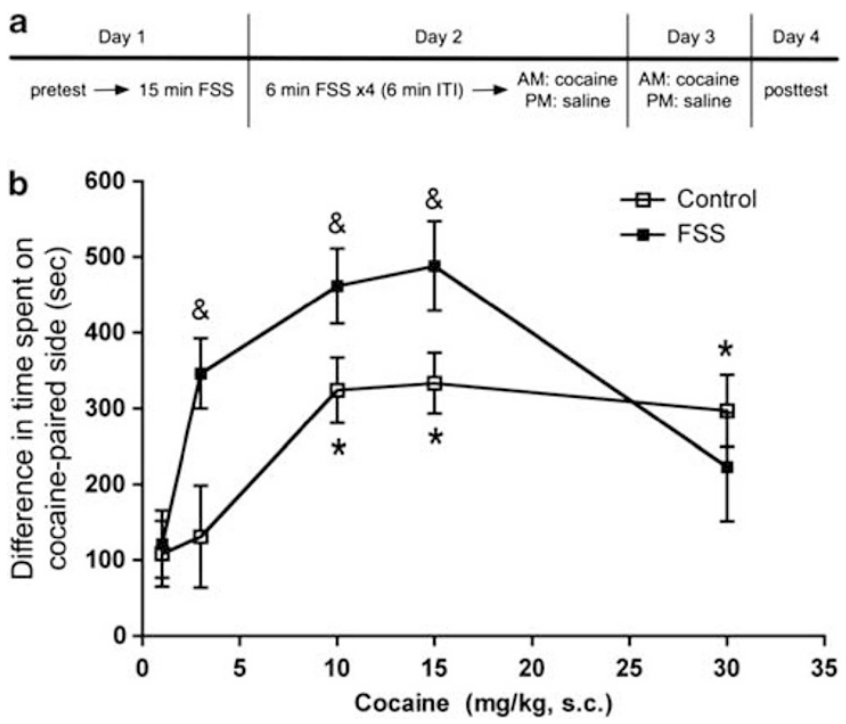

Figure 2 Exposure to FSS before CPP training affects the cocaine-CPP dose-response relationship. (a) Diagram summarizing the training protocol. Mice were exposed to repeated FSS or allowed to remain in their home cage without swimming, before 2 days of cocaine and saline conditioning (see Materials and methods). (b) Mice were trained using cocaine doses of either 1, 3, 5, 10, 15, or $30 \mathrm{mg} / \mathrm{kg}$ (s.c.) and subsequent place preference times were measured to generate dose-response relationships for stressed and unstressed animals. Data show a potentiation of cocaine-CPP in animals exposed to FSS before training as compared with untreated controls. Data are mean \pm SEM. Untreated control mice trained with 10 , 15 , or $30 \mathrm{mg} / \mathrm{kg}$ cocaine showed significant place preference. $*$ denotes $p<0.05$, one-sample $t$-test, $n=9-22$ mice. FSS caused a significant potentiation compared with unstressed controls at 3,10 , or $15 \mathrm{mg} / \mathrm{kg}$ cocaine; \& denotes $p<0.05$, two-way ANOVA followed by Fisher's LSC multiple-comparison post hoc test, $n=9-22$ mice.

after FSS, a modified warm water $\left(52.5^{\circ} \mathrm{C}\right)$ tail-withdrawal assay was used (McLaughlin et al, 2003).

\section{Conditioned Place Preference}

WT C57Bl/6 mice were used in a three-compartment placeconditioning apparatus as described earlier (McLaughlin et al, 2003). The CPP apparatus consisted of two large Plexiglas outer compartments separated by a smaller inner compartment. The two outer compartments were made visually distinct with $2.5 \mathrm{~cm}$ wide alternating black and white strips oriented either vertically or horizontally, whereas the smaller inner chamber was completely white. Movement through each compartment was recorded using video capture (Canon ZR90) from above and analyzed using Noldus Ethovision software (version 3.0; Noldus, Wageningen, The Netherlands).

For studies involving KOR activation before CPP training (Figure 2a), the experimental protocol was as described earlier (McLaughlin et al, 2003). Briefly, on day 1 of testing, initial place preference bias was assessed by placing each animal in the small central compartment and recording time spent in each compartment while having free access to the entire apparatus for $30 \mathrm{~min}$. After initial preference testing, some mice were exposed to FSS. On days 2 and 3, mice received cocaine $(15 \mathrm{mg} / \mathrm{kg}$, s.c.) in the morning and confined to their drug-paired compartment for $30 \mathrm{~min}$, and then $4 \mathrm{~h}$ later received saline ( $10 \mathrm{ml} / \mathrm{kg}$ of body weight, s.c.) in the afternoon and confined to their assigned salinepaired compartment for $30 \mathrm{~min}$. On day 2, cocaine training began within $10 \mathrm{~min}$ of the last FSS trial. On day 4, the final preference test was assessed by placing each animal in the small central compartment and allowing free access to the entire apparatus for $30 \mathrm{~min}$ and recording time spent in each compartment. On the basis of this behavioral protocol, it is conceivable that the chamber associated with exposure to FSS may become positively associated with 'relief from stress.' We earlier addressed this potential confound by training animals with saline in both chambers, but having one of the chambers consistently associated with removal from the second day of FSS (the 'relief' chamber). Vehicleconditioned animals did not show a preference or aversion to the 'relief' chamber when either unstressed or exposed to FSS (McLaughlin et al, 2003).

For studies involving KOR activation before the final preference test, the outer-compartment floors were both covered with a depth of approximately $1-2 \mathrm{~cm}$ of shredded wood chip bedding (Beta chip, NEPCO, Warrensburg, NY), whereas the center chamber remained uncovered. To ensure a low basal stress level, experimental animals were briefly handled each day for 4 days and each mouse received one mock s.c. and one mock i.p. injection before behavioral testing ('mock' means needle inserted, but no fluid injected). On day 1 of testing, initial place preference bias was assessed by placing each animal in the small central compartment and recording time spent in each compartment while having free access to the entire apparatus for $30 \mathrm{~min}$; mice spending $>720 \mathrm{~s}$ in the inner chamber or spending double the amount of time in one of the outer chambers over the other outer chamber were excluded from the study $(n=34)$. An unbiased design was used: approximately half the animals received cocaine in their non-preferred chamber $(n=134)$ and half in their preferred chamber $(n=130)$, and pretest time spent in the subsequently drug-paired box was equivalent to pretest time spent in the subsequently saline-paired box (drug-paired box mean $=669 \pm 9.3 \mathrm{~s} \quad(n=264) ; \quad$ saline-paired box mean $=680 \pm 10.3 \mathrm{~s} \quad(n=264)$; unpaired samples $t$-test; $p>0.05)$. On days 2 and 3 , mice received saline $(10 \mathrm{ml} / \mathrm{kg}$ of body weight, s.c.) in the morning and confined to their assigned saline-paired compartment for $30 \mathrm{~min}$, and then $4 \mathrm{~h}$ later received cocaine $(15 \mathrm{mg} / \mathrm{kg}$, s.c.) in the afternoon and confined to their drug-paired compartment for $30 \mathrm{~min}$. On day 4, the final preference test was assessed by placing each animal in the small central compartment and allowing free access to the entire apparatus for $30 \mathrm{~min}$ and recording time spent in each compartment. Cocaine-CPP scores were calculated as time spent in the drug-paired compartment pre-training subtracted from time spent in the drug-paired compartment post-training and plotted using Graph Pad Prism 4.0 (San Diego, CA). For studies involving U50,488 administration before the final preference test, animals were administered saline $(10 \mathrm{ml} / \mathrm{kg}$ of body weight, i.p.) $60 \mathrm{~min}$ earlier or U50,488 (5 mg/kg, i.p.) 5, 30, 60, 90, or $120 \mathrm{~min}$ before beginning the final preference test. Another set of animals were administered U50,488 $(2.5,5$, or $10 \mathrm{mg} / \mathrm{kg}$, i.p.) $60 \mathrm{~min}$ before beginning the final preference test. Some animals received norBNI $(10 \mathrm{mg} / \mathrm{kg}$, i.p.) $2-18 \mathrm{~h}$ before administration of either saline or U50,488 $(5 \mathrm{mg} / \mathrm{kg}$, i.p.) $60 \mathrm{~min}$ before beginning the final preference test. The 
norBNI's antagonistic effects are maximal at $1 \mathrm{~h}$ after administration and persist $>21$ days (Bruchas et al, 2007b). For studies involving acute FSS exposure before the final preference test, animals were exposed to one $15 \mathrm{~min}$ FSS 10 or $45 \mathrm{~min}$ before beginning the final preference test. Some animals received norBNI $(10 \mathrm{mg} / \mathrm{kg}$, i.p.) $2-18 \mathrm{~h}$ before exposure to one $15 \mathrm{~min}$ FSS 10 min before beginning the final preference test. For studies involving repeated FSS exposure before the final preference test, animals were exposed to one $15 \mathrm{~min}$ FSS $4 \mathrm{~h}$ after completion of cocaine training on day 3. On day 4 , animals were exposed to four 6 min swims and began the final preference test $10 \mathrm{~min}$ after FSS completion. Some animals received norBNI $2 \mathrm{~h}$ before exposure to FSS on day 3.

\section{Novel Object Recognition (NOR) Assay}

The effects of KOR agonist administration on memory retrieval was assessed using the NOR assay. The NOR assay depends on an animal's natural tendency to explore a novel object more than a familiar object (Ennaceur and Delacour, 1988). The NOR apparatus was an open field $(40 \times 20 \times$ $20 \mathrm{~cm}^{3}$ ). To ensure a low basal stress level, experimental animals were briefly handled each day for 5 days, and each mouse received one mock i.p. injection before behavioral testing. On days 1-3, animals were habituated in the empty open field for $30 \mathrm{~min}$. Multiple habituations were used to further lower basal stress levels. On day 4, animals received three 6 min training sessions each separated by $10 \mathrm{~min}$ in which they were presented with two identical objects (A1 and A2). The objects were coverslip boxes and were placed opposite each other $3.5 \mathrm{~cm}$ from each wall (see Figure 5bi.) On day 5, animals were administered saline $60 \mathrm{~min}$ earlier or U50,488 ( $5 \mathrm{mg} / \mathrm{kg}$, i.p.) 15 or $60 \mathrm{~min}$ before beginning the 6 min NOR test. Some animals were pretreated with norBNI ( $10 \mathrm{mg} / \mathrm{kg}$, i.p.) $2 \mathrm{~h}$ before saline or U50,488 administration. In the NOR test, animals were exposed to a familiar object (A2) and a novel object (B) (see Figure 5bi). The novel object was a top from a 11 bottle and A2 and B were placed in the same locations as $\mathrm{A} 1$ and $\mathrm{A} 2$ were placed in the training sessions. Object exploration was measured by stopwatch, and 'exploration' was defined as sniffing or touching the object with the nose. Behavior was not scored as 'exploration' when the animal was using the object to rear up or when the animal was sitting on the object. Data are expressed as a recognition index (RI). For each training session, $\mathrm{RI}=$ time exploring $\mathrm{A} 1 /$ (total time spent exploring $\mathrm{A} 1+\mathrm{A} 2$ ), and for the NOR test, $\mathrm{RI}=$ time exploring $\mathrm{B} /$ (total time spent exploring $\mathrm{B}+\mathrm{A} 2)$. To ensure that a pre-training bias did not exist for one object over the other, a separate group of mice were habituated to the open field for $30 \mathrm{~min}$ and then $10 \mathrm{~min}$ later received a NOR test. No basal differences in exploration of objects $\mathrm{A}$ and $\mathrm{B}$ were detected ( $\mathrm{RI}=0.49 \pm 0.02, n=8$ ). To assess locomotion, each session was recorded using video capture (Canon ZR90) from above and analyzed using Noldus Ethovision software.

\section{Data Analysis}

Data are expressed as means \pm SEM. Differences between groups were determined using one-way ANOVA followed by Dunnet's post hoc (for comparisons between relevant groups to the control group) or Bonferroni's post hoc test if the main effect was significant at $p<0.05$. Difference in maximal response was determined using a paired or unpaired samples $t$-test. For experiments having a $2 \times 2$ factorial design, two-way ANOVAs followed by Fisher's LSC multiple-comparison post hoc test or Bonferroni's post hoc test if an interaction effect was significant at $p<0.05$. For the NOR assay, within-group comparisons were made using a paired samples $t$-test to determine whether there was an increase in RI from the training phase to the testing phase. Statistical analyses were conducted using Graph Pad Prism 4.0 (San Diego, CA).

\section{RESULTS}

\section{FSS Before CPP Training Changes the Cocaine-CPP Dose-Response Relationship}

Earlier reports have shown that activation of the KOR system before cocaine-CPP training, either through administration of the $\kappa$-agonist U50,488 or exposure to FSS, produce a time-dependent potentiation of cocaine-CPP (McLaughlin et al, 2003; McLaughlin et al, 2006a). Mice in those studies were trained using $15 \mathrm{mg} / \mathrm{kg}$ (s.c.) cocaine only; therefore, we first determined the dose-response relationship for cocaine-CPP after FSS and for non-stressed controls. In non-stressed controls, doses of 10, 15, and $30 \mathrm{mg} / \mathrm{kg}$ cocaine gave equivalent CPP responses $(10 \mathrm{mg} / \mathrm{kg}$ mean $=324 \pm 43.2 \mathrm{~s} \quad(n=12), 15 \mathrm{mg} / \mathrm{kg}$ mean $=334 \pm 40.2 \mathrm{~s}$ $(n=22), 30 \mathrm{mg} / \mathrm{kg}$ mean $=297 \pm 47.5 \mathrm{~s} \quad(n=16)$, one-way ANOVA; $F_{2,49}=0.19, p>0.5$ ) (Figure 2). Mice subjected to repeated FSS before 3,10 , or $15 \mathrm{mg} / \mathrm{kg}$ cocaine conditioning showed enhanced CPP responses $(3 \mathrm{mg} / \mathrm{kg}$ mean $=346 \pm 46.1 \mathrm{~s}(n=17), 10 \mathrm{mg} / \mathrm{kg}$ mean $=462 \pm 49.6 \mathrm{~s}$ $(n=15), 15 \mathrm{mg} / \mathrm{kg}$ mean $=488 \pm 59.0 \mathrm{~s} \quad(n=11)$, one-way ANOVA; $\left.F_{2,40}=2.29, p>0.5\right)$. The CPP responses were significantly potentiated at each of these doses (two-way ANOVA; main effect of swim, $\mathrm{F}_{1,129}=7.54, p<0.05$; main effect of cocaine dose, $\mathrm{F}_{4,129}=11.54, p<0.0001$; interaction of swim cocaine dose, $\mathrm{F}_{4,129}=2.45, p<0.05$; Fisher's LSD multiple-comparison post hoc test, $p<0.05$ ) (Figure 2). In contrast, FSS did not significantly potentiate the CPP response to $30 \mathrm{mg} / \mathrm{kg}$ (Figure 2). The effect of FSS under these training conditions was to shift the cocaine-CPP doseresponse curve upward (as shown by significantly enhanced response at 3,10 , and $15 \mathrm{mg} / \mathrm{kg}$ cocaine) and to the left (as shown by a significant preference at $3 \mathrm{mg} / \mathrm{kg}$ cocaine for FSS exposed animals, but not in mice not subjected to FSS). Analysis of the dose-response relationship indicates that the potentiation was not solely observed at one dose and suggests that the rewarding properties of cocaine were generally increased by earlier stress exposure. The lack of potentiation at $30 \mathrm{mg} / \mathrm{kg}$ cocaine is consistent with earlier reports of an inverted U-shaped cocaine dose response (Bardo et al, 1995; Caine et al, 2000; Tzschentke, 2007).

\section{Potentiation of Cocaine-CPP After Direct KOR Agonist-Induced Activation Before Expression of Cocaine-CPP}

Mice were trained in the standard cocaine-CPP protocol using $15 \mathrm{mg} / \mathrm{kg}$ cocaine (s.c.) without experiencing 


\begin{tabular}{c|c|c|c} 
Day 1 & Day 2 & Day 3 & Day 4 \\
\hline pretest & $\begin{array}{c}\text { AM: saline } \\
\text { PM: cocaine }\end{array}$ & $\begin{array}{c}\text { AM: saline } \\
\text { PM: cocaine }\end{array}$ & saline/U50,488 $\stackrel{5,30,60,90, \text { or } 120 \text { min }}{\longrightarrow}$ posttest
\end{tabular}
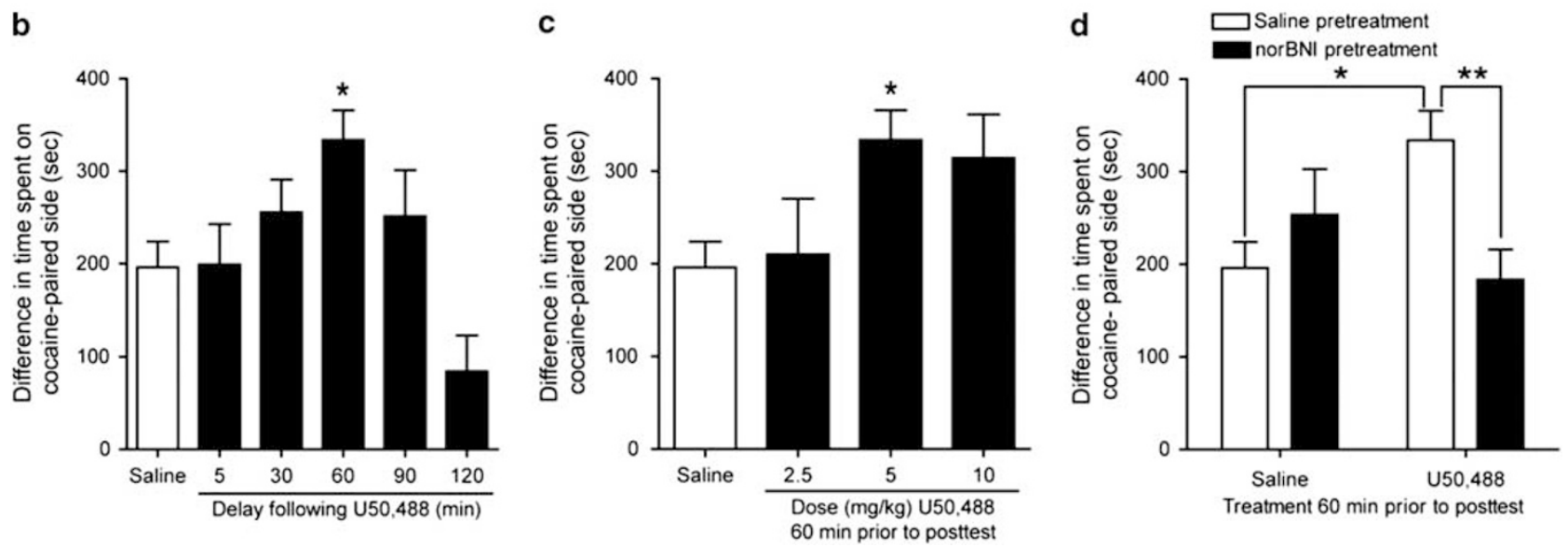

Figure 3 Pretreatment with KOR agonist before the final preference test is sufficient to produce a time and dose-dependent potentiation of cocaine CPP that is norBNI sensitive. (a) Timeline of the protocol in which U50,488 was given before the final preference test. (b) Preference test data showing a time-dependent U50,488 induced potentiation of cocaine-CPP. * denotes $p<0.05$, significant difference in cocaine-CPP for mice treated with U50,488 60 min before preference test compared with saline-treated mice, one-way ANOVA followed by Dunnet's post hoc test, $n=10-20$ mice per bar. (c) Preference test data showing a dose-dependent U50,488-induced potentiation of cocaine-CPP. Data show significant potentiation of cocaine-CPP with administration of $U 50,488$ at $5 \mathrm{mg} / \mathrm{kg}$, but not 2.5 or $10 \mathrm{mg} / \mathrm{kg}$. * denotes $p<0.05$, significant difference in cocaine-CPP of U50,488 (5 mg/kg, i.p.)-treated mice as compared with saline-treated mice, one-way ANOVA followed by Dunnet's post hoc test, $n=12-20$. (d) Preference test data showing a norBNI sensitive, U50,488 induced potentiation of cocaine-CPP. Data show that potentiation of cocaine-CPP by U50,488 was blocked by pretreatment with norBNI. NorBNI alone had no effect on cocaine-CPP as compared with saline-treated animals. * denotes $p<0.05$, significant difference in cocaine-CPP of U50,488-treated mice as compared with saline controls, *** denotes $p<0.01$, significant difference in cocaine-CPP of U50,488-treated animals as compared with norBNI pretreated, U50,488-treated animals, two-way ANOVA followed by Bonferroni's post hoc test, $n=10-19$. Data are mean \pm SEM.

either U50,488 or FSS before the conditioning sessions. On day 4, cocaine-conditioned mice were administered U50,488 (5 mg/kg, i.p.) $5,30,60,90$, or $120 \mathrm{~min}$ before final preference testing (as illustrated in Figure 3a). KOR activation by $\mathrm{U} 50,48860$ min before expression of cocaineCPP significantly potentiated cocaine-CPP compared with saline-pretreated mice $(n=10-21$; one-way ANOVA; $\mathrm{F}_{5,83}=4.96, p<0.0005$; Dunnet's post hoc U50,488-60 min $(n=21)$ vs saline $(n=21), p<0.05)$. In contrast, KOR activation 5, 30, 90, or $120 \mathrm{~min}$ before expression of cocaine-CPP did not significantly alter place preference expression $(p>0.05)$ (Figure $3 \mathrm{a})$. We also asked whether potentiation of cocaine-CPP after KOR activation by U50,488 before the final preference test was dose dependent by administering either $2.5,5$, or $10 \mathrm{mg} / \mathrm{kg}$ U50,488 (i.p.) at $60 \mathrm{~min}$ before expression of cocaine-CPP. Significant cocaine-CPP potentiation was obtained at the U50,488 dose of $5 \mathrm{mg} / \mathrm{kg}\left(n=12-21\right.$; one-way ANOVA; $\mathrm{F}_{3,68}=3.09$, $p<0328$; Dunnet's post hoc U50,488-5 mg/kg $(n=21)$ $v s$ saline $(n=21), p<0.05)$, but was absent at 2.5 and $10 \mathrm{mg} / \mathrm{kg}$ U50,488 $(p>0.05)$, although there was a trend toward significance at $10 \mathrm{mg} / \mathrm{kg}$ U50,488 (Figure $3 c$ ). The narrow dose-effect window may be a consequence of the hypo-locomotor effects at $10 \mathrm{mg} / \mathrm{kg}$ U50,488 as compared with 2.5 or $5 \mathrm{mg} / \mathrm{kg}$ U50,488 (Kuzmin et al, 2000).
Potentiation of Cocaine-CPP by Direct KOR AgonistInduced Activation Before Expression of Cocaine-CPP is Blocked by norBNI Pretreatment

To confirm KOR mediation, mice were pretreated with the selective $\kappa$-receptor antagonist norBNI $(10 \mathrm{mg} / \mathrm{kg}$, i.p.). Pretreated mice did not show potentiation of cocaine-CPP after U50,488 $(5 \mathrm{mg} / \mathrm{kg}$, i.p.) administration $60 \mathrm{~min}$ before the final preference test $(n=10-19$; two-way ANOVA; interaction of norBNI $\times \mathrm{U} 50,488, \mathrm{~F}_{1,66}=9.00, p<0.004$; followed by Bonferroni's post hoc, U50,488 $(n=21)$ vs norBNI + U50,488 $\quad(n=19) \quad p<0.01) \quad$ (Figure $3 \mathrm{~d})$. In addition, norBNI alone did not affect expression of cocaine-CPP as saline controls and mice administered norBNI before administration of saline show comparable cocaine-CPP. These results suggest that potentiation after U50,488 administration before expression of cocaine-CPP is mediated by activation of the KOR system.

\section{Potentiation of Cocaine-CPP After Repeated FSS, but Not Acute FSS, Before Expression of Cocaine-CPP}

To assess whether acute exposure to FSS would also potentiate cocaine-CPP when given after conditioning, mice were exposed to one $15 \mathrm{~min}$ FSS episode and then began preference testing within 10 min of being taken out of the 


\begin{tabular}{l|c|c|c} 
Day 1 & Day 2 & Day 3 & Day 4 \\
\hline pretest & $\begin{array}{c}\text { AM: saline } \\
\text { PM: cocaine }\end{array}$ & $\begin{array}{c}\text { AM: saline } \\
\text { PM: cocaine }\end{array}$ & 15 min FSS $\stackrel{10 \text { or } 45 \text { min }}{\longrightarrow}$ posttest
\end{tabular}

\begin{tabular}{|c|c|c|c|}
\hline Day 1 & Day 2 & Day 3 & Day 4 \\
\hline pretest & $\begin{array}{l}\text { AM: saline } \\
\text { PM: cocaine }\end{array}$ & $\begin{array}{l}\text { AM: saline } \\
\text { PM: cocaine }\end{array} \rightarrow 15$ min FSS & $6 \min$ FSS $\times 4(6 \mathrm{~min} I \mathrm{TI}) \rightarrow$ posttest \\
\hline
\end{tabular}

c

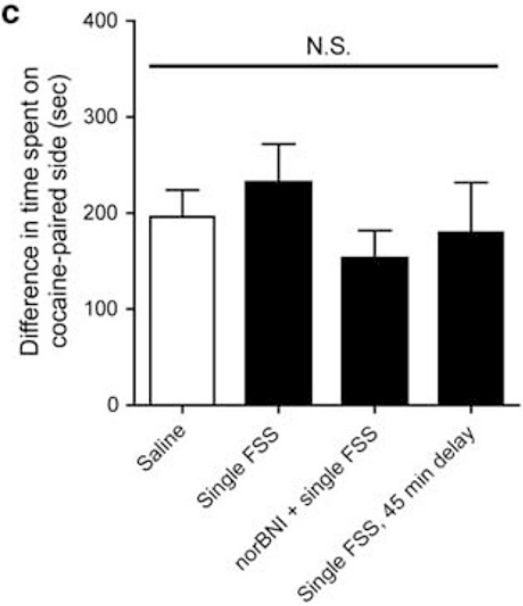

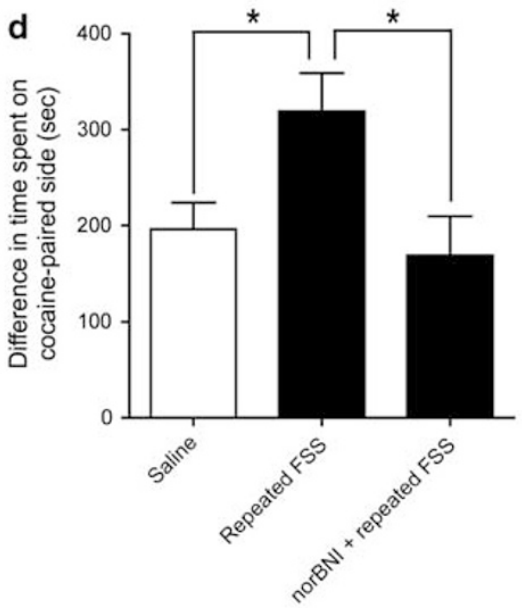

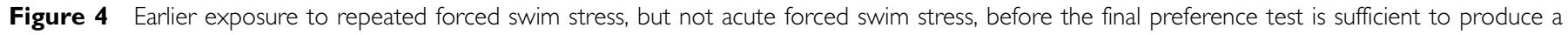

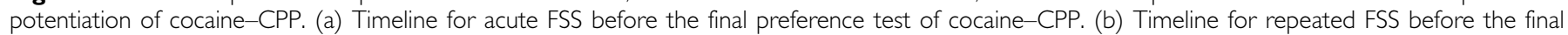

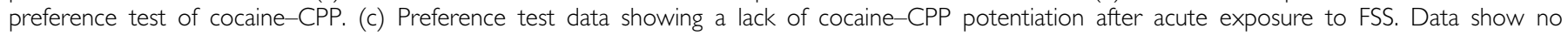

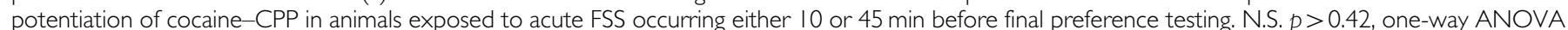

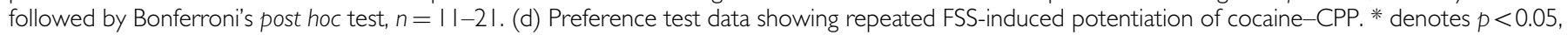

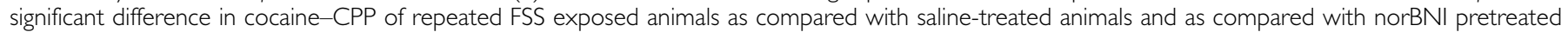
repeated FSS exposed animals, one-way ANOVA followed by Bonferroni's post hoc test, $n=10-20$. Data are mean \pm SEM.

water and towel dried (Figure 4a). As evident in Figure 4c, mice exposed to a single FSS episode did not show potentiation of cocaine-CPP $(n=11-20$; one-way ANOVA; $\mathrm{F}_{3,64}=0.953, p>0.05$ compared with non-stressed saline controls). Pretreatment of acutely stressed animals with $10 \mathrm{mg} / \mathrm{kg}$ norBNI (i.p.) also did not affect cocaine-CPP (Figure 4c). To confirm that the single FSS exposure released dynorphin, a modified warm water tail-withdrawal assay was used (McLaughlin et al, 2003). As earlier shown, the single $15 \mathrm{~min}$ episode of FSS produced significant norBNI-sensitive increase in tail-withdrawal latency (mean pre-swim $=1.41 \pm 0.08 \mathrm{~s} ; \quad$ post-swim $=3.4 \pm 0.19 \mathrm{~s}$, norBNI-treated pre-swim $=1.15 \pm 0.07 \mathrm{~s}$, norBNI-treated post-swim $=1.98 \pm 0.14 \mathrm{~s} ; \quad n=18-20 ; \quad$ two-way ANOVA; interaction of norBNI times swim, $\mathrm{F}_{1,73}=5.82, p<0.018$ ).

Potentiation was seen after U50,488 administration at 60 , but not $30 \mathrm{~min}$ before the final preference test. The acute swim began $25 \mathrm{~min}$ before the final preference test and thus may not have resulted in potentiation because this time point fell before the required hour time point seen with U50,488. Therefore, a different set of animals was exposed to one $15 \mathrm{~min}$ FSS and then began the final preference test $45 \mathrm{~min}$ after being taken out and towel dried (Figure $4 \mathrm{a}$ ). As with the acute swim occurring $25 \mathrm{~min}$ before the final preference test, these animals did not display cocaine-CPP potentiation as compared with control animals $(n=11-20$; one-way ANOVA; $\mathrm{F}_{3,64}=0.9525, p>0.05$ ) (Figure $4 \mathrm{c}$ ). As with the $25 \mathrm{~min}$ group, these animals also showed an increase in tail-withdrawal latency (mean preswim $=1.8 \pm 0.07 \mathrm{~s} ; \quad$ post-swim $=3.1 \pm 0.24 \mathrm{~s}$ ), suggesting that the dynorphin/KOR system was activated.

To assess whether repeated exposure to FSS would potentiate cocaine-CPP when given after conditioning, mice were exposed to one $15 \mathrm{~min}$ FSS on day 3, 2-4 h after completion of cocaine associative learning and four $6 \mathrm{~min}$ swims on day 4, ending $10 \mathrm{~min}$ before expression of place preference (Figure 4b). Mice exposed to repeated FSS showed significant potentiation of cocaine-CPP as compared with saline controls $(n=10-21$; one-way ANOVA; $\mathrm{F}_{2,39}=4.14, p<0.023$; followed by Bonferroni's post hoc, saline $\quad(n=21) \quad$ vs saline + swim $\quad(n=10) \quad p<0.05)$ (Figure $4 \mathrm{~d}$ ). The magnitude of potentiation was equivalent to that produced by direct KOR activation through administration of $\mathrm{U} 50,488$ ( $5 \mathrm{mg} / \mathrm{kg}$, i.p.) $60 \mathrm{~min}$ before final preference test (mean U50,488-60 $\mathrm{min}=334 \pm 32.1 \mathrm{~s}$; $n=21$; mean FSS $=319 \pm 39.8 \mathrm{~s} ; n=10)$. The potentiation produced by repeated FSS was blocked by pretreatment with KOR antagonist norBNI (10 mg/kg, i.p.); administration of norBNI $2 \mathrm{~h}$ before the first FSS on day 3 produced a subsequent cocaine-CPP response that did not significantly differ from untreated saline controls, but did differ from repeated FSS animals pretreated with saline (Bonferroni's post hoc, saline $(n=21)$ vs swim + norBNI $(n=13) p>0.05$ and swim $(n=10)$ vs norBNI + swim $(n=13) p<0.05)$. After the second day of FSS, tail-withdrawal latencies were also significantly increased in a norBNI-sensitive manner 


\begin{tabular}{c|c|c} 
a & Day 1-3 & Day 5 \\
\hline habituation to chamber & 6 min training sessions $\times 3($ ITI $=10 \mathrm{~min})$ & saline $/$ U50,488 $\stackrel{15 \text { or } 60 \mathrm{~min}}{\longrightarrow}$ novel object recognition test
\end{tabular}
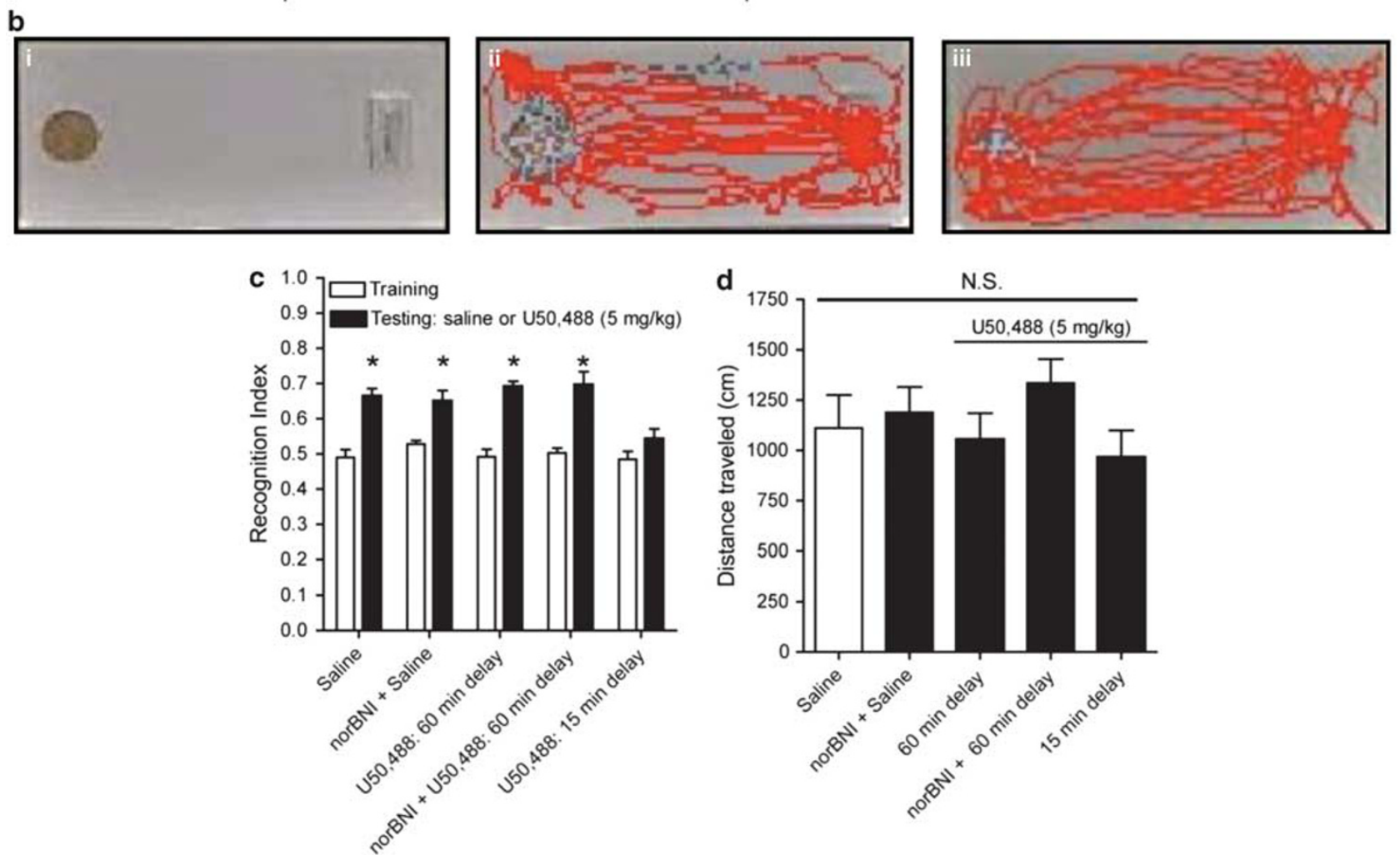

Figure 5 KOR agonist-induced activation has a time-dependent effect on memory retrieval as assessed by the NOR assay. (a) Timeline of NOR assay. (b, i) Representative picture of the NOR testing chamber. The object of the left is the novel object (B) and the object on the right is the familiar object (A2). During training, novel object B was replaced with another object identical to A2 and is called Al. (b, ii) Representative trace of a 6 min locomotion pattern for an animal administered saline 60 min before NOR testing. (b, iii) Representative trace of a 6 min locomotion pattern for an animal administered U50,488 60 min before NOR testing. (c) U50,488 treatment I5, but not 60 min before NOR testing inhibits memory retrieval. The recognition index (RI) increase from training session to NOR testing does not differ for animals administered U50,488 60 min before NOR testing as compared with saline controls. Pretreatment with norBNI also does not change the RI increase as compared with saline controls. Animals receiving U50,488 I5 min before NOR testing show an inhibition of memory retrieval. * denotes $p<0.05$ significant increase in RI from training to testing sessions, paired samples $t$-test, $n=8-16$. (d) Locomotion in NOR testing does not change after either U50,488 and/or norBNI administration. There were no significant differences between treatment groups. N.S. $p>0.63$, one-way ANOVA, $n=8-16$. Data are means \pm SEM.

(mean pre-swim $=1.84 \pm 0.16 \mathrm{~s}$, post-swim $=2.98 \pm 0.15 \mathrm{~s}$, norBNI-pretreated pre-swim $=1.74 \pm 0.11 \mathrm{~s}$, norBNI-pretreated post-swim $=2.2 \pm 0.18 \mathrm{~s} ; n=10-20$; two-way ANOVA; interaction of norBNI times swim, $\mathrm{F}_{1,37}=12.45, p<0.032$ ) confirming that stress-induced dynorphin release was initiated after repeated FSS. Together, these results suggest that KOR activation by either agonist or repeated FSS, but not acute FSS, induced release of endogenous dynorphins to enhance the rewarding valence of the cocaineassociated cues.

\section{U50,488 Administration 60 min Before NOR Testing Does Not Alter Memory Retrieval}

The NOR assay was used to investigate the effects of KOR agonist-induced activation on memory retrieval (Ennaceur and Delacour, 1988). Mice were given saline $(10 \mathrm{ml} / \mathrm{kg}$ of body weight, i.p.) or U50,488 (5 mg/kg, i.p.) $60 \mathrm{~min}$ before NOR testing on day 5 (Figure $5 \mathrm{a}$ ). Saline-treated mice displayed an increase in RI during NOR testing as compared with the NOR training phase $(n=16$; paired samples $t$-test; $p<0.005$ ) (Figure 5c). Animals administered U50,488 $60 \mathrm{~min}$ before NOR testing also showed an increase in RI during NOR testing as compared with the NOR training phase $(n=12$; paired samples $t$-test; $p<0.0001)$. Separate groups of animals were pretreated with norBNI $(10 \mathrm{mg} / \mathrm{kg}$, i.p.) $2 \mathrm{~h}$ before saline or U50,488 administration. Animals pretreated with norBNI and then administered saline before NOR testing displayed an increase in RI $(n=10$; paired samples $t$-test; $p<0.003$ ) and animals pretreated with norBNI and then administered U50,488 $60 \mathrm{~min}$ before NOR testing also displayed an increase in RI $(n=8$; paired samples $t$-test; $p<0.04$ ). All four groups showed equivalent RIs during training and equivalent RI increase during NOR testing (training: $n=8-16$; one-way ANOVA; $\mathrm{F}_{4,47}=2.2$, $p>0.05$; testing: $n=8-16$; one-way ANOVA; $\mathrm{F}_{4,47}=1.8$, $p>0.05$ ) (Figure 5c).

As KOR activation can produce anxiety-like responses (Knoll et al, 2007; Bruchas et al, 2009b), we recorded distance traveled during the NOR test and found no 
difference across the groups ( $n=8-16$; one-way ANOVA; $\mathrm{F}_{4,47}=0.7, p>0.05$ ) (Figure $5 \mathrm{~d}$ ). Both saline- and U50,488treated animals crossed the center of the open field and representative traces of locomotion are shown for saline (Figure 5bii)- and U50,488 (Figure 5biii)-treated animals. Earlier reports showed an effect of acute KOR activation on memory retrieval (Castellano et al, 1988; Daumas et al, 2007); therefore, we also investigated the effects of acute U50,588 administration on NOR retrieval. Animals receiving U50,488 (5 mg/kg, i.p.) $15 \mathrm{~min}$ before NOR testing did not display a significant increase in RI ( $n=8$; paired sample $t$-test; $p>0.07$ ) (Figure $5 \mathrm{c}$ ) confirming that acute U50,488 administration inhibits memory retrieval.

\section{DISCUSSION}

The principal finding of this study is that KOR activation before the presentation of cocaine-associated cues enhances approach behaviors to those cues. On the basis of our evidence, the alternative hypotheses that KOR mediated potentiation of cocaine-CPP is dependent on enhanced associative learning mechanisms or memory retrieval were not supported. These results suggest that the stress-induced potentiation of cocaine-CPP described earlier (McLaughlin et al, 2003, 2006a, b) may be caused by a dynorphin/KORdependent increase in the rewarding valence of cocaine and cocaine-associated cues.

To investigate the possibility that stress may shift the pharmacological dose-response relationship between cocaine and subsequent place preference, we characterized the amount of place preference conditioned by administering different doses of cocaine to mice that had either been exposed or not to FSS. These data suggest that FSS-treated animals show a leftward shift in their cocaine doseresponse relationship as FSS-treated animals showed a significant preference for $3 \mathrm{mg} / \mathrm{kg}$ cocaine, whereas control, unstressed animals did not. In addition, the potentiation of cocaine-CPP does not seem to be equivalent to an increase in dose; maximal cocaine-CPP response was significantly greater in those animals exposed to FSS than those not exposed. This result is consistent with Haile et al (2001) who showed a leftward shift in the dose-response relationship for cocaine-CPP after chronic unpredictable stress in rats. In addition, rhesus monkeys trained to choose between cocaine and food that were administered U50,488 also showed a leftward shift in the cocaine-choice, doseresponse curve, and a decrease in $\mathrm{ED}_{50}$ for $\mathrm{U} 50,488$-treated animals at $0.32 \mathrm{mg} / \mathrm{kg} / \mathrm{h}$ cocaine (Negus, 2004).

Interestingly, mice trained on $30 \mathrm{mg} / \mathrm{kg}$ cocaine did not show a significant potentiation of cocaine-CPP after FSS exposure. Earlier studies have shown that cocaine has an inverted U-shaped dose response in which the highest doses produce a diminished response (Bardo et al, 1995; Caine et al, 2000; Tzschentke, 2007). This inverted U-shaped dose-response curve in a CPP assay is rationalized as resulting from aversive effects of high cocaine doses. The lower response of FSS-treated mice at 30 than $15 \mathrm{mg} / \mathrm{kg}$ cocaine is consistent with a leftward shift in the inverted U-shaped dose response. Although a full inverted U-shaped dose-response curve was not generated for control mice in this study, it seems plausible that doses higher than $30 \mathrm{mg} / \mathrm{kg}$ would be aversive and decrease place preference based on published work (Bardo et al, 1995; Caine et al, 2000; Tzschentke, 2007). Haile et al (2001) also found similar results; rats exposed to chronic unpredictable stress showed a potentiated place preference to $5 \mathrm{mg} / \mathrm{kg}$ cocaine as compared with controls, but a lower response to $7.5 \mathrm{mg} / \mathrm{kg}$ cocaine, suggesting an inverted U-shaped dose response for animals exposed to unpredictable stress. Interestingly, control animals in that earlier study also did not show a full inverted U-shaped dose response, which is similar to the dose response generated using our control mice. Thus, our data fit with the model that stress causes shifts in the doseresponse relationship, and we conclude that FSS exposure increases the apparent efficacy for cocaine. The increase in apparent cocaine efficacy seen after FSS may contribute to a dynorphin/KOR-dependent increase in the rewarding valence of cocaine and cocaine-associated cues and thus underlie stress-induced potentiation of cocaine-CPP.

The alternative explanation that stress-induced dynorphin release may potentiate cocaine-CPP amplitude by enhancing associative learning processes was also plausible (Schwarzer, 2009). However, dynorphin is generally thought to suppress learning mechanisms, and activation of KOR blocks LTP induction in the hippocampus (Wagner et al, 1993), an important neuronal process and brain region for learning and memory. In addition, animals having elevated hippocampal dynorphin levels show memory deficits, not enhancements (Sandin et al, 1998). CA3 hippocampal microinjections of U50,488 decreased context-induced freezing in a fear-conditioning paradigm (Daumas et al, 2007), and earlier exposure to FSS produced deficits in an NOR task (Carey et al, 2009), suggesting a negative effect of $\mathrm{KOR}$ activation on learning. However, after administration of various KOR agonists, some reports have shown positive effects on learning (Hiramatsu and Hoshino, 2004; Hiramatsu and Watanabe, 2006; Kuzmin et al, 2006), although in these earlier studies, norBNI did not completely reverse the effects and thus the agonist may be acting through non- $\hat{e}$-opioid sites. In this study, potentiation of cocaine-CPP could be evoked by stress-induced dynorphin release or U50,488-induced KOR activation after the conditioning had been completed, thus we conclude that an enhancement of associative learning mechanisms was not responsible.

The other phases of learning and memory subsequent to the initial associative learning phase are 'consolidation,' 'retrieval,' and 'expression' processes. Consolidation occurs during the hours after a learning event (McGaugh et al, 1996; McGaugh and Roozendaal, 2009), and could potentially be affected by KOR activation. However, U50,488 administration $30 \mathrm{~min}$ after cocaine conditioning failed to affect place preference (McLaughlin et al, 2006a). In the present paradigm, the potentiation of cocaine-CPP by U50,488 occurred $>24 \mathrm{~h}$ after the associative learning sessions were completed. Thus, we conclude that an effect on consolidation mechanisms is unlikely.

Acutely, KOR activation has been shown to inhibit memory retrieval (Castellano et al, 1988), and this was confirmed in this study using the NOR test. When U50,488 was administered before passive avoidance testing, mice displayed decreased memory retention (Castellano et al, 1988, de Quervain et al, 1998). In addition, rats showed a 
decreased performance in a water-maze spatial memory task after footshock given before retention testing (de Quervain et al, 1998). One advantage of the NOR test of memory retrieval for this analysis of stress mechanisms is that both the passive avoidance and the water-maze assay are inherently stressful to the animal, whereas NOR is not (Ennaceur and Delacour, 1988). Although a separate effect on memory expression could not be distinguished from an effect on retrieval in the NOR assay, no evidence of enhancement of either retrieval or expression by agonistinduced KOR activation was evident in this study. Lack of enhancement theoretically may have been the result of a ceiling effect in the NOR assay, although based on earlier literature showing an inhibitory, not enhancing, effect of stress or KOR activation on memory retrieval, this alternative explanation seems unlikely. In summary, because KOR activation acutely suppresses learning and memory mechanisms and no enhancement of these parameters was evident during the critical time interval necessary for KORdependent enhancement of cocaine-CPP, the most parsimonious explanation for the potentiation of CPP is that KOR activation enhanced the rewarding valence of cocaine without affecting associative learning mechanisms responsible for acquisition, consolidation, retrieval, or expression.

The potentiation of cocaine-CPP by repeated FSS or U50,488 was blocked by norBNI pretreatment in this study, and in earlier studies, potentiation was not evident in knockout mice lacking functional dynorphin of KOR genes (McLaughlin et al, 2003, 2006a). These results indicate that stress-induced release of dynorphin and subsequent activation of the KOR system mediates the potentiation of cocaine reward. Although dynorphin-dependent effects are evident after an acute swim session (Redila and Chavkin, 2008; Bruchas et al, 2009b), multiple swims are required to see stress-dependent effects such as immobility in the FSS (McLaughlin et al, 2003) and activation of the mitogenactivated protein kinases (MAPK) p38 and extracellular signal-regulated kinases (Bruchas et al, 2007a, 2008). In addition, activation of p38 MAPK is required for KORmediated place aversion (Bruchas et al, 2007a; Land et al, 2009); therefore, lack of cocaine-CPP potentiation seen after a single FSS may be a result of lack of p38 MAPK activation and the animal's subsequent aversive experience. In contrast, p38 MAPK activation is evident after a single injection of U50,488, which suggests that pharmacological activation may be a more sustained or robust stimulus. Consistent with this distinction, a single injection of U50,488 was found to potentiate CPP in this study, whereas multiple FSS trials were required.

Stress-induced potentiation of the rewarding properties of drugs of abuse has been earlier established (Piazza et al, 1990; Will et al, 1998; McLaughlin et al, 2003; Covington and Miczek, 2005; Koob and Kreek, 2007). Stress or direct KOR activation has also been shown to reinstate cocaine-CPP (Sanchez and Sorg, 2001; Carey et al, 2007; Redila and Chavkin, 2008; Land et al, 2009). Stress-induced dynorphin release and pharmacological activation of KOR also results in conditioned place aversion (CPA) in rodents (Shippenberg and Herz, 1986; Land et al, 2008), and $\kappa$-agonists induce reports of dysphoria in human beings (Pfeiffer et al, 1986). Whether the dynorphin-dependent mechanisms underlying potentiation, reinstatement, and aversion are identical is not yet clear. They may have roots in similar dysphoria/anxiety mechanisms or may result from actions on distinct neuronal circuits. Further analysis of the brain circuits, cellular sites, and signaling mechanisms responsible will be important in identifying the fundamental mechanisms.

The concept that modulation of hedonic state can affect cocaine valence and subsequent motivation has been earlier suggested (Ahmed et al, 2002; Negus, 2004; Solinas et al, 2008) and draws from the allostatic model of addiction (Koob and Le Moal, 2008; Bruchas et al, 2010). Ahmed et al (2002) showed that increases in intracranial self-stimulation (ICSS) threshold lead to increases in cocaine intake and attributed these effects to a decrease in hedonic state resulting from prolonged cocaine withdrawal. Using a concurrent self-administration procedure, Negus (2004) investigated the effects of U50,488 on cocaine self-administration in rhesus monkeys. Importantly, the author attributes the U50,488 induced leftward shift in the cocaine-choice dose-effect curve to increased reinforcing value of cocaine in comparison with food. Alternatively, Solinas et al (2008) showed that environmental enrichment, a manipulation shown to be anti-depressive, attenuated cocaine-CPP. KOR activation produces dysphoria in human beings (Pfeiffer $e t$ al, 1986) and depression-like behaviors in rodents (Mague et al, 2003). Specifically KOR activation results in swim stress-induced immobility and social defeat behaviors during SDS (McLaughlin et al, 2003, 2006b) and an increase in ICSS (Carlezon et al, 2006; Tomasiewicz et al, 2008). More recent work has examined the effects of KOR activation on the motivational effects of stress (Land $e t$ al, 2008). In this study, mice that learned to associate a neutral odorant with FSS later showed CPA to that odorant. Dynorphin gene deletion or administration of the selective KOR antagonist norBNI blocked this avoidance behavior. In addition, direct KOR activation, through treatment with the $\kappa$-agonist U69593, results in CPA (Shippenberg and Herz, 1986). Although this study did not directly test the conclusion that KOR activation can modulate reward valence, from the current results and earlier data, it is plausible to hypothesize that KOR activation produces hedonic deficits that may subsequently increase the rewarding and motivational properties of cocaine and/or associated cues to return the animal to a state of hedonic equilibrium.

In conclusion, this study supports the hypothesis that KOR activation potentiates place preference by modulating the valence of cocaine and/or cocaine-associated cues and suggests a possible mechanism for stress-induced potentiation of cocaine-CPP. This study highlights the potential for the dynorphin/KOR system as drug targets for treatment of disorders such as addiction and depression.

\section{ACKNOWLEDGEMENTS}

This work was supported by USPHS grants DA07278, DA25970, DA20570, and an award from the Hope for Depression Research Foundation. We thank Dan Messinger for genotyping the mice and maintaining the breeding colony. Dr Michael Garelick (University of Washington) and Dr Julie Blendy (University of Pennsylvania) provided helpful comments. 


\section{DISCLOSURE}

A Schindler has no conflict of interest to disclose. S Li is currently employed by Astrazeneca, but had no conflict of interest during her participation in this study, which solely involved the generation of the data shown in Figure 2 . C Chavkin has no conflict of interest or consulting relationships to disclose, but has received outside compensation for seminars on his NIH-funded research during the last 3 years at Astrazeneca Corp, Wilmington DE (2/25/08); National Institute on Drug Abuse, Bethesda, MD (2/26/08); Department of Pharmacology at the University of California, Irvine (6/9/08); Department of Pharmacology at the Uniformed Services University, Bethesda, MD (11/13/08); Neurobiology Program, University of Minnesota, Minneapolis, MN (4/24/09); Sepracor Corporation, Boston MA (6/12/09); Eli Lilly Corporation, Indianapolis, IN (10/27/09); Adolor Corporation, Exton, PA (11/5/09); Neurosciences Program at Vanderbilt University $(2 / 17 / 10)$. He received a customary honorarium for each of these talks. In addition, C Chavkin served as a grant reviewer for NIH on 10/12/09, $1 / 8 / 10$, and $3 / 10 / 10$ and received a customary honorarium for his CSR-review committee service.

\section{REFERENCES}

Ahmed SH, Kenny PJ, Koob GF, Markou A (2002). Neurobiological evidence for hedonic allostasis associated with escalating cocaine use. Nat Neurosci 5: 625-626.

Bardo MT, Rowlett JK, Harris MJ (1995). Conditioned place preference using opiate and stimulant drugs: a meta-analysis. Neurosci Biobehav Rev 19: 39-51.

Bruchas MR, Land BB, Aita M, Xu M, Barot SK, Li S et al (2007a). Stress-induced p38 mitogen-activated protein kinase activation mediates kappa-opioid-dependent dysphoria. J Neurosci 27: 11614-11623.

Bruchas MR, Land BB, Chavkin C (2010). The dynorphin/kappa opioid system as a modulator of stress-induced and proaddictive behaviors. Brain Res 1314: 44-55.

Bruchas MR, Land BB, Lemos JC, Chavkin C (2009b). CRF1-R activation of the dynorphin/kappa opioid system in the mouse basolateral amygdala mediates anxiety-like behavior. PLoS One 4: e8528.

Bruchas MR, Yang T, Schreiber S, Defino M, Kwan SC, Li S et al (2007b). Long-acting kappa opioid antagonists disrupt receptor signaling and produce noncompetitive effects by activating c-Jun N-terminal kinase. J Biol Chem 282: 29803-29811.

Bruchas MR, Xu M, Chavkin C (2008). Repeated swim stress induces kappa opioid-mediated activation of extracellular signal-regulated kinase 1/2. Neuroreport 19: 1417-1422.

Caine SB, Negus SS, Mello NK (2000). Effects of dopamine D(1like) and $\mathrm{D}(2$-like) agonists on cocaine self-administration in rhesus monkeys: rapid assessment of cocaine dose-effect functions. Psychopharmacology (Berl) 148: 41-51.

Carey AN, Borozny K, Aldrich JV, McLaughlin JP (2007). Reinstatement of cocaine place-conditioning prevented by the peptide kappa-opioid receptor antagonist arodyn. Eur J Pharmacol 569: 84-89.

Carey AN, Lyons AM, Shay CF, Dunton O, McLaughlin JP (2009). Endogenous kappa opioid activation mediates stress-induced deficits in learning and memory. J Neurosci 29: 4293-4300.

Carlezon Jr WA, Beguin C, DiNieri JA, Baumann $\mathrm{MH}$, Richards MR, Todtenkopf MS et al (2006). Depressive-like effects of the kappa-opioid receptor agonist salvinorin A on behavior and neurochemistry in rats. J Pharmacol Exp Ther 316: 440-447.
Castellano C, Libri V, Ammassari-Teule M (1988). The amygdala mediates the impairing effect of the selective kappa-opioid receptor agonist U-50,488 on memory in CD1 mice. Behav Brain Res 30: 259-263.

Chavkin C (2000). Dynorphins are endogenous opioid peptides released from granule cells to act neurohumorly and inhibit excitatory neurotransmission in the hippocampus. Prog Brain Res 125: 363-367.

Chavkin C, Goldstein A (1981). Demonstration of a specific dynorphin receptor in guinea pig ileum myenteric plexus. Nature 291: 591-593.

Chavkin C, James IF, Goldstein A (1982). Dynorphin is a specific endogenous ligand of the kappa opioid receptor. Science 215: 413-415.

Covington III HE, Miczek KA (2005). Intense cocaine selfadministration after episodic social defeat stress, but not after aggressive behavior: dissociation from corticosterone activation. Psychopharmacology (Berl) 183: 331-340.

Daumas S, Betourne A, Halley H, Wolfer DP, Lipp HP, Lassalle JM et al (2007). Transient activation of the CA3 kappa opioid system in the dorsal hippocampus modulates complex memory processing in mice. Neurobiol Learn Mem 88: 94-103.

de Quervain DJ, Roozendaal B, McGaugh JL (1998). Stress and glucocorticoids impair retrieval of long-term spatial memory. Nature 394: 787-790.

Ennaceur A, Delacour J (1988). A new one-trial test for neurobiological studies of memory in rats. 1: behavioral data. Behav Brain Res 31: 47-59.

Goeders NE, Guerin GF (1994). Non-contingent electric footshock facilitates the acquisition of intravenous cocaine self-administration in rats. Psychopharmacology (Berl) 114: 63-70.

Gold PW, Chrousos GP (2002). Organization of the stress system and its dysregulation in melancholic and atypical depression: high vs low CRH/NE states. Mol Psychiatry 7: 254-275.

Haile CN, GrandPre T, Kosten TA (2001). Chronic unpredictable stress, but not chronic predictable stress, enhances the sensitivity to the behavioral effects of cocaine in rats. Psychopharmacology (Berl) 154: 213-220.

Haney M, Maccari S, Le Moal M, Simon H, Piazza PV (1995). Social stress increases the acquisition of cocaine self-administration in male and female rats. Brain Res 698: 46-52.

Hiramatsu M, Hoshino T (2004). Involvement of kappa-opioid receptors and sigma receptors in memory function demonstrated using an antisense strategy. Brain Res 1030: 247-255.

Hiramatsu M, Watanabe E (2006). Dynorphin A (2-13) improves mecamylamine-induced learning impairment accompanied by reversal of reductions in acetylcholine release in rats. Neuropeptides 40: 47-56.

Knoll AT, Carlezon Jr WA (2010). Dynorphin, stress, and depression. Brain Res 1314: 56-73.

Knoll AT, Meloni EG, Thomas JB, Carroll FI, Carlezon Jr WA (2007). Anxiolytic-like effects of kappa-opioid receptor antagonists in models of unlearned and learned fear in rats. J Pharmacol Exp Ther 323: 838-845.

Koob G, Kreek MJ (2007). Stress, dysregulation of drug reward pathways, and the transition to drug dependence. Am J Psychiatry 164: 1149-1159.

Koob GF, Le Moal M (2005). Plasticity of reward neurocircuitry and the 'dark side' of drug addiction. Nat Neurosci 8: 1442-1444.

Koob GF, Le Moal M (2008). Addiction and the brain antireward system. Annu Rev Psychol 59: 29-53.

Kreibich AS, Briand L, Cleck JN, Ecke L, Rice KC, Blendy JA (2009). Stress-induced potentiation of cocaine reward: a role for CRF R1 and CREB. Neuropsychopharmacology 34: 2609-2617.

Kuzmin A, Madjid N, Terenius L, Ogren SO, Bakalkin G (2006). Big dynorphin, a prodynorphin-derived peptide produces NMDA receptor-mediated effects on memory, anxiolytic-like and 
locomotor behavior in mice. Neuropsychopharmacology 31: 1928-1937.

Kuzmin A, Sandin J, Terenius L, Ogren SO (2000). Dose- and timedependent bimodal effects of kappa-opioid agonists on locomotor activity in mice. J Pharmacol Exp Ther 295: 1031-1042.

Land BB, Bruchas MR, Lemos JC, Xu M, Melief EJ, Chavkin C (2008). The dysphoric component of stress is encoded by activation of the dynorphin kappa-opioid system. J Neurosci 28: 407-414.

Land BB, Bruchas MR, Schattauer S, Giardino WJ, Aita M, Messinger D et al (2009). Activation of the kappa opioid receptor in the dorsal raphe nucleus mediates the aversive effects of stress and reinstates drug seeking. Proc Natl Acad Sci USA 106: 19168-19173.

Mague SD, Pliakas AM, Todtenkopf MS, Tomasiewicz HC, Zhang Y, Stevens Jr WC et al (2003). Antidepressant-like effects of kappa-opioid receptor antagonists in the forced swim test in rats. J Pharmacol Exp Ther 305: 323-330.

McGaugh JL, Cahill L, Roozendaal B (1996). Involvement of the amygdala in memory storage: interaction with other brain systems. Proc Natl Acad Sci USA 93: 13508-13514.

McGaugh JL, Roozendaal B (2009). Drug enhancement of memory consolidation: historical perspective and neurobiological implications. Psychopharmacology (Berl) 202: 3-14.

McLaughlin JP, Land BB, Li S, Pintar JE, Chavkin C (2006a). Prior activation of kappa opioid receptors by U50,488 mimics repeated forced swim stress to potentiate cocaine place preference conditioning. Neuropsychopharmacology 31: 787-794.

McLaughlin JP, Li S, Valdez J, Chavkin TA, Chavkin C (2006b). Social defeat stress-induced behavioral responses are mediated by the endogenous kappa opioid system. Neuropsychopharmacology 31: 1241-1248.

McLaughlin JP, Marton-Popovici M, Chavkin C (2003). Kappa opioid receptor antagonism and prodynorphin gene disruption block stress-induced behavioral responses. J Neurosci 23: 5674-5683.

Negus SS (2004). Effects of the kappa opioid agonist U50,488 and the kappa opioid antagonist nor-binaltorphimine on choice between cocaine and food in rhesus monkeys. Psychopharmacology (Berl) 176: 204-213.

Pfeiffer A, Brantl V, Herz A, Emrich HM (1986). Psychotomimesis mediated by kappa opiate receptors. Science 233: 774-776.

Piazza PV, Deminiere JM, Maccari S, Mormede P, Le Moal M, Simon H (1990). Individual reactivity to novelty predicts probability of amphetamine self-administration. Behav Pharmacol 1: 339-345.

Pliakas AM, Carlson RR, Neve RL, Konradi C, Nestler EJ, Carlezon Jr WA (2001). Altered responsiveness to cocaine and increased immobility in the forced swim test associated with elevated
cAMP response element-binding protein expression in nucleus accumbens. J Neurosci 21: 7397-7403.

Porsolt RD, Le Pichon M, Jalfre M (1977). Depression: a new animal model sensitive to antidepressant treatments. Nature 266: 730-732.

Redila VA, Chavkin C (2008). Stress-induced reinstatement of cocaine seeking is mediated by the kappa opioid system. Psychopharmacology (Berl) 200: 59-70.

Sanchez CJ, Sorg BA (2001). Conditioned fear stimuli reinstate cocaine-induced conditioned place preference. Brain Res 908: 86-92.

Sandin J, Nylander I, Georgieva J, Schott PA, Ogren SO, Terenius L (1998). Hippocampal dynorphin B injections impair spatial learning in rats: a kappa-opioid receptor-mediated effect. Neuroscience 85: 375-382.

Schwarzer C (2009). 30 years of dynorphins - new insights on their functions in neuropsychiatric diseases. Pharmacol Ther 123: 353-370.

Shaham Y, Erb S, Stewart J (2000). Stress-induced relapse to heroin and cocaine seeking in rats: a review. Brain Res Brain Res Rev 33: 13-33.

Shippenberg TS, Herz A (1986). Differential effects of mu and kappa opioid systems on motivational processes. NIDA Res Monogr 75: 563-566.

Sinha R, Garcia M, Paliwal P, Kreek MJ, Rounsaville BJ (2006). Stress-induced cocaine craving and hypothalamic-pituitaryadrenal responses are predictive of cocaine relapse outcomes. Arch Gen Psychiatry 63: 324-331.

Solinas M, Chauvet C, Thiriet N, El Rawas R, Jaber M (2008). Reversal of cocaine addiction by environmental enrichment. Proc Natl Acad Sci USA 105: 17145-17150.

Tomasiewicz HC, Todtenkopf MS, Chartoff EH, Cohen BM, Carlezon Jr WA (2008). The kappa-opioid agonist U69,593 blocks cocaine-induced enhancement of brain stimulation reward. Biol Psychiatry 64: 982-988.

Tzschentke TM (2007). Measuring reward with the conditioned place preference (CPP) paradigm: update of the last decade. Addict Biol 12: 227-462.

Wagner JJ, Terman GW, Chavkin C (1993). Endogenous dynorphins inhibit excitatory neurotransmission and block LTP induction in the hippocampus. Nature 363: 451-454.

Will MJ, Watkins LR, Maier SF (1998). Uncontrollable stress potentiates morphine's rewarding properties. Pharmacol Biochem Behav 60: 655-664.

Zhou Y, Cui CL, Schlussman SD, Choi JC, Ho A, Han JS et al (2008). Effects of cocaine place conditioning, chronic escalatingdose 'binge' pattern cocaine administration and acute withdrawal on orexin/hypocretin and preprodynorphin gene expressions in lateral hypothalamus of Fischer and Sprague-Dawley rats. Neuroscience 153: 1225-1234. 